\title{
DIAGNOSA KEPERAWATAN PADA PASIEN HIPERTENSI DI RUMAH SAKIT
}

\section{Kiki Ramadhani}

\author{
Email : Kikiirmdhn@gmail.com
}

\section{Latar Belakang}

Menurut Undang-undang No. 44 Tahun 2009 Rumah Sakit adalah institusi pelayanan kesehatan bagi masyarakat dengan karakteristik tersendiri yang dipengaruhi oleh perkembangan ilmu pengetahuan kesehatan, kemajuan teknologi, dan kehidupan sosial ekonomi masyarakat yang harus tetap mampu meningkatkan pelayanan yang lebih bermutu dan terjangkau oleh masyarakat agar terwujud derajat kesehatan yang setinggi-tingginya. Salah satu masalah yang sering muncul di institusi rumah sakit adalah pasien hipertensi. Hipertensi adalah tekanan darah persisten dimana tekanan sistoliknya diatas $140 \mathrm{mmHg}$ dan tekanan diastoliknya diatas $90 \mathrm{mmHg}$ (Smeltzer, Bare, 2002). Berdasarkan penyebabnya hipertensi dibagi menjadi 2 golongan, yaitu: pertama Hipertensi Esensial atau hipertensi primer yang tidak diketahui penyebabnya, disebut juga hipertensi idiopatik. faktor yang mempengaruhinya seperti genetik, lingkungan, hiperaktifitas. Meskipun hipertensi primer belum diketahui dengan pasti penyebabnya, data penelitian telah menemukan beberapa faktor yang sering menyebabkan terjadinya hipertensi, faktor tersebut yaitu: Faktor keturunan, Ciri Perorangan dan Kebiasaan hidup (Kowalski, Robert, 2010). Kedua Hipertensi Sekunder atau renal yaitu hipertensi yang disebabkan oleh penyakit lain. Merupakan $10 \%$ dari seluruh kasus hipertensi adalah hipertensi sekunder, Faktor pencetus munculnya hipertensi sekunder antara lain ; penggunaan kontrasepsi oral, neurogenik ( tumor otak, ensefalitis, gangguan psikiatris ), kehamilan, peningkatan tekanan intravaskuler, luka bakar dan stress. (Udjianti, Wajan, 2011 ).

\section{Metode}

Metode yang digunakan dengan melakukan analisis data sekunder yaitu dengan mengumpulkan kajian pustaka terhadap beberapa referensi yang mendukung . Referensi-Referensi tersebut meliputi pembahasan yang bertujuan untuk mengetahui bagaimana pelaksanaan diagnosa keperawatan pada pasien hipertensi yang terjadi 
di rumah sakit.

\section{Hasil}

Hipertensi merupakan proses kompleks dari beberapa organ utama dan sistem, meliputi jantung, pembuluh darah, saraf, hormon dan ginjal Isolated Systolic Hypertension adalah hipertensi yang terjadi ketika tekanan sistolik lebih dari 140 $\mathrm{mmHg}$ namun tekanan diastolik dalam batas normal. Keadaan ini berhubungan dengan arteriosclerosis (pengerasan dinding arteri). Pregnancy Induced Hypertension adalah kondisi naiknya tekanan darah yang terjadi selama kehamilan, dimana naiknya tekanan darah sistolik dan diastolik lebih dari $15 \mathrm{mmHg}$ (Guibert $\mathrm{R}$ dan Franco ED, 1999). Meningkatnya tekanan darah di dalam arteri bisa terjadi melalui beberapa cara salah satunya melalui peningkatan pompa jantung sehingga mengalirkan lebih banyak cairan pada setiap detiknya. Kondisi ini menyebabkan arteri besar kehilangan kelenturannya sehingga tidak dapat mengembang pada saat darah melalui arteri tersebut. Dengan demikian setiap denyut jantung, darah dipaksa melalui pembuluh yang lebih sempit dibandingkan biasanya dan menyebabkan naiknya tekanan darah. Kondisi itulah yang terjadi pada usia lanjut, dimana dinding arteri telah menebal dan kaku karena arteriosklerosis. mekanisme ini juga berlaku ketika arteri kecil (arteriola) untuk sementara waktu mengerut karena perangsangan saraf atau hormon di dalam darah (Susanto, 2010). Selain itu faktor - faktor yang mempengaruhi kejadian hipertensi adalah usia, jenis kelamin, faktor genetik, faktor stres, kegemukan atau obesitas, konsumsi garam yang berlebihan, merokok, narkoba, alkohol, kafein, kurangnya berolahraga, kolesterol tinggi(Wulandari, 2011). Rencana tindakan atau intervensi keperawatan yang telah dibuat untuk menangani masalah risiko perfusi serebral tidak efektif yang berhubungan dengan Hipertensi tersebut diantaranya adalah dengan melakukan pengkajian secara komprehensif terkait keluhan utama pasien yaitu nyeri kepala hebat. Pengkajian yang dilakukan secara langsung kepada pasien, setelah dilakukan pengkajiaan terkait keluhan pasien kemudian dilakukan pengkajian secara objektif meliputi kondisi umum pasien, obeservasi Tanda-tanda vital dan observasi kesadaran pasien, kaji capillary refill, GCS, warna dalam kelembapan kulit, kaji tanda peningkatan TIK (kaku kuduk, muntah proyektil danpenurunan kesadaran serta adanya peningkatan nilai MAP), monitor 
adanya tromboplebitis, berikan $\mathrm{O}^{2}$ sesuai kebutuhan, berikan pasien posisi elevasi, kepala ditinggikan $30^{\circ}$, kolaborasi dengan dokter dalam pemberian terapi medik, lakukan pemeriksaan laboratorium dan pemeriksaan radiologi, yang harapannya setelah dilakukan intervensi tersebut masalah risiko perfusi serebral tidak efektif dapat teratasi dengan kriteria hasil Pasien dapat mendemonstrasikan status sirkulasi yang ditandai dengan tekanan systole dan diastole dalam rentang yang diharapkan, tidak ada tanda-tanda peningkatan tekanan intracranial yang ditandai dengan nilai MAP yang meningkat, serta dapat mendemonstrasikan kemampuan kognitif yang ditandai dengan berkomunikasi dengan jelas dan sesuai dengan kemampuan, menunjukkan perhatian, Emergensi konsentrasi dan orientasi, kemudian dapat memproses informasi, serta dapat menunjukkan fungsi sensori motori cranial yang utuh: tingkat kesadaran membaik, tidak ada gerakan-gerakan involunter.

\section{Pembahasan}

Istilah hipertensi diambil dari bahasa Inggris hypertension yang berasal dari bahasa Latin "hyper" dan "tension. "Hyper" berarti super atau luar biasa dan "tension" berarti tekanan atau tegangan. Hypertension akhirnya menjadi istilah kedokteran yang populer untuk menyebut penyakit tekanan darah tinggi. Tekanan darah adalah tenaga yang dipakai oleh darah yang dipompakan dari jantung untuk melawan tahanan pembuluh darah, jika tekanan darah seseorang meningkat dengan tajam dan kemudian menetap tinggi, orang tersebut dapat dikatakan mempunyai tekanan darah tinggi atau hipertensi (Gunawan, 2001). Hipertensi adalah peningkatan abnormal pada tekanan sistolik $140 \mathrm{mmHg}$ atau lebih dan tekanan diatolik 120 $\mathrm{mmHg}$. Hipertensi dapat didefinisikan sebagai tekanan darah persisten, di mana tekanan sistoliknya di atas $140 \mathrm{mmHg}$ dan diastolik di atas $90 \mathrm{mmHg}$. Pada populasi lansia, hipertensi didefinisikan sebagai tekanan sistolik $160 \mathrm{mmHg}$ dan tekanan diastolik $90 \mathrm{mmHg}$. Menurut WHO 1996, batasan tekanan darah normal orang dewasa adalah maksimum 140/90 mmHg. Apabila tekanan darah seseorang di atas angka tersebut pada beberapa kali pengukuran di waktu yang berbeda, orang tersebut bisa dikatakan menderita hipertensi. Penderita hipertensi memiliki resiko lebih besar untuk mendapatkan serangan jantung dan stroke (Suwarsa, 2006). Selain itu terdapat kondisi yang dinamakan White Coat Hypertension. Bentuk hipertensi ini adalah meningkatnya tekanan darah yang terjadi selama kunjungan ke dokter, 
namun tidak di rumah. Hipertensi ini merupakan faktor pada kira- kira $20 \%$ pasien dengan hipertensi ringan (Guibert R \& Franco ED, 1999). Hipertensi merupakan masalah kesehatan masyarakat dunia yang dapat terjadi baik di negara maju maupun negara berkembang. Hipertensi disebut juga dengan "silent killer" karena pada sebagian kasus tidak menunjukan gejala apapun. Hipertensi tidak terjadi secara tiba - tiba, melainkan melalui proses yang berlangsung cukup lama. Hipertensi diidentifikasikan melalui hasil pemeriksaan rata - rata tekanan darah sistolik $>140 \mathrm{mmHg}$, dan tekanan darah diastolik $>90 \mathrm{mmHg}$. Dengan demikian dapat disimpulkan bahwa tekanan darah yang mencapai $>140 / 90 \mathrm{mmHg}$ dengan dua kali pengukuran merupakan keadaan hipertensi. Hipertensi juga dijuluki sebagai silent killer atau pembunuh diam-diam karena penyakit ini tidak memiliki gejala yang spesifik, hipertensi dapat menyerang siapa saja, dan kapan saja, serta dapat menimbulkan penyakit degeneratif, hingga kematian. Menurut beberapa penelitian, orang yang mederita hipertensi memiliki peluang 12 kali lebih besar untuk terkena stoke dan 6 kali lebih besar untuk terkena serangan jantung. Penyakit hipertensi biasanya tidak disadari oleh masyarakat karena gejalanya yang belum jelas dan menyerupai keluhan kesehatan pada umumnya. Penderita baru mengetahui bahwa dirinya terserang hipertensi setelah dilakukan pemeriksaan tekanan darah, atau setelah timbulnya penyakit lain. Berdasarkan data World Health Organization (WHO) tahun 2011 menunjukkan satu milyar orang di dunia menderita hipertensi dengan prevalensi 26,4\%. Di negara maju prevalensi mencapai 37,3\% dua sepertiga diantaranya berada di negara berkembang. Prevalensi hipertensi akan terus meningkat secara signifikan dan pada tahun 2025 diprediksi akan terjadi peningkatan sebanyak $29 \%$ total populasi dewasa dunia. Tingginya prevalensi hipertensi menjadikan faktor risiko terjadinya penyakit kardiovaskular akan lebih tinggi. Menurut WHO hipertensi menyebabkan setidaknya 45\% kematian. Diagnosis keperawatan merupakan penilaian klinis terhadap pengalaman atau respon individu, keluarga, atau komunitas pada masalah kesehatan, pada risiko masalah kesehatan, atau pada proses kehidupan.

Diagnosis keperawatan merupakan bagian vital dalam menentukan asuhan keperawatan yang sesuai untuk membantu klien mencapai kesehatan yang optimal (SDKI, 2016). Hal yang menyebabkan klien mengalami peningkatan tekanan darah yaitu gaya hidup klien yang monoton, dikarenakan klien kalau dirumah jarang 
beraktifitas, hanya dirumah saja, kurang berolah raga, pola makan yang tidak baik dimana klien tidak suka mengkonsumsi sayur dan buah, klien lebih suka mengkonsumsi makanan yang berlemak dan kolesterol. Adapun keluhan yang menunjukkan tanda dan gejala penyakit hipertensi yaitu pusing, rasa berat di tengkuk, peningkatan tekanan darah dari batas normal, mual dan muntah. Diagnosa keperawatan yang ditemukan pada kasus dan sesuai dengan teori:

1. Gangguan perfusi jaringan serebral berhubungan dengan peningkatan tekanan intrakranial. Gangguan perfusi jaringan serebral adalah suatu keadaan dimana individu mengalami penurunan dalam nutrisi dan oksigenasi pada tingkat selular sehubungan dengan kurangnya suplai darah kapiler. ( Carpenito, 2009 ). prioritas pertama pada penyakit hipertensi jika tidak segera ditangani akan muncul masalah lain yaitu komplikasi penyakit stroke, gagal jantung.

2. Gangguan nutrisi, kurangnya nutrisi dari kebutuhan tubuh berhubungan dengan intake yang tidak adekuat. Gangguan nutrisi kurang dari kebutuhan tubuh adalah suatu keadaan ketika individu yang tidak puasa mengalami atau beresiko mengalami penurunan berat badan yang berhubungan dengan intake yang tidak adekuat. ( Carpenito, 2009)

3. Intolerasi aktivitas berhubungan dengan kelemahan fisik Intoleransi aktivitas adalah ketidakcukupan energi secara fisiologis maupun psikologis untuk men eruskan/menyelesaikan aktifitas yang diminta atau aktivitas sehari- hari. ( NANDA, 2007 ) C.

Pelaksanaan diagnosis keperawatan pada pasien hipertensi antara lain:

$\checkmark$ melakukan pengkajian dan menanyakan keluhan pasien

$\checkmark$ melakukan pemeriksaan tanda - tanda vital

$\checkmark$ mengajarkan teknik napas dalam

$\checkmark$ memberikan tindakan nonfarmakologis yaitu memberikan pijatan pada pundak

$\checkmark$ memberikan obat oral analsik $2 \times 2 \mathrm{mg}$ dalam 24 jam

$\checkmark$ memberikan injeksi gastrofer $25 \mathrm{mg} / 12$ jam obat masuk melalui selang infus. 
Pelaksanaan tindakan yang dilakukan atau implementasi didasarkan atas intervensi yang disusun sebelumnya, untuk diagnosa 2 tindakan keperawatan yang dilakukan yaitu:

$\checkmark$ mengobservasi keadaan umum pasien

$\checkmark$ menanyakan keluhan pasien

$\checkmark$ memberikan makanan ringan tambahan pada pasien sesuai dengan diit hipertensi.

$\checkmark$ memberikan injeksi dexametazone $5 \mathrm{mg} / 8$ jam obat masuk melalui selang infus, carnevit 1 vial/24 jam, ceftriaxone $1 \mathrm{gr} / 12$ jam, dan brain act $250 \mathrm{mg} / 12$ jam obat masuk melalui selang infus

$\checkmark$ mengobservasi keadaan umum pasien.

Berdasarkan diagnosa dan intervensi diatas, maka tindakan keperawatan yang dilakukan untuk diagnosa ke 3 yaitu

$\checkmark$ melakukan pemeriksaan tanda - tanda vital dan menanya keluhan pasien

$\checkmark$ memberikan injeksi dexa $5 \mathrm{mg} / 8$ jam, carnevit 1 vial/24 jam, ceftriaxone 1 $\mathrm{gr} / 12$ jam, obat masuk melalui selang infus,

$\checkmark$ perawat mengajarkan pasien untuk menggerakkan tangannya dan menekukkan kaki, membantu pasien untuk memenuhi kebutuhannya, membantu pasien untuk duduk,

$\checkmark$ menganjurkan keluarga untuk selalu membantu pasien untuk memenuhi kebutuhannya.

Berdasarkan dari data pengkajian dapat dirumuskan diagnosa keperawatan yaitu risiko perfusi serebral tidak efektif dan nyeri akut, diagnosa yang diprioritaskan adalah risiko perfusi serebral tidak efektif hal ini sejalan dengan teori Standar Diagnosis Keperawatan Indonesia (SDKI, 2017) yang menyatakan bahwa risiko perfusi serebral tidak efektif adalah keadaan yang berisiko mengalami penurunan sirkulasi darah ke otak yang dapat mengganggu kesehatan. Dengan karakteristik dari faktor risiko yaitu keabnormalan masa protrombin dan/atau masa 
tromboplastin persial, penurunan kinerja ventrikel kiri, aterosklerosis aorta, diseksi arteri, fibrilasi atrium, tumor otak, stenosis karotis, miksoma atrium, aneurisma serebri, koagulopati misal anemia sel sabit, dilatasi kardiomiopati, koagulasi intravaskuler diseminata, embolisme, cedera kepala, hiperkolesteronemia, hipertensi, Emergensi endokarditis infektif, katub prostetik mekanis, stenosis mitral, neoplasma otak, infark miokard akut, sindrom sick sinus, penyalahgunaan zat, terapi tombolitik, efek samping tindakan misalnya tindakan operasi bypass. Serta didukung dengan kondisi klinis terkait yaitu stroke, cedera kepala, aterosklerotik aorta, infark miokard akut, diseksi arteri, embolisme, endokarditis infektif, fibrilasi atrium, hiperkolesterolemia, hipertensi, dilatasi kardiomiopati, koagulasi intravaskular diseminata, miksoma atrium, neoplasma otak, segmen ventrikel kiri akinetik, sindrome sick sinus, stenosis karotid, stenosis mitral, hidrosefaluse, infesi otak misalnya miningitis, ensefalitis, abses serebri. Alasan memprioritaskan diagnosa keperawatan ini yaitu karena dapat mengancam nyawa dan jika tidak segera dilakukan tindakan medis serta asuhan keperawatan dapat megakibatkan kematian. Seperti yang diketahui bahwa hipertensi atau penyakit tekanan darah tinggi adalah suatu keadaan kronis yang ditandai dengan meningkatnya tekanan darah pada dinding pembuluh darah arteri. Keadaan tersebut mengakibatkan jantung bekerja lebih keras untuk mengedarkan darah ke seluruh tubuh melalui pembuluh darah. Hal ini dapat mengganggu aliran darah, merusak pembuluh darah, bahkan menyebabkan penyakit degeneratif, hingga kematian(ed. Yunita, 2017).

\section{Penutup}

Hipertensi adalah peningkatan abnormal pada tekanan sistolik $140 \mathrm{mmHg}$ atau lebih dan tekanan diatolik $120 \mathrm{mmHg}$. Hipertensi dapat didefinisikan sebagai tekanan darah persisten, di mana tekanan sistoliknya di atas $140 \mathrm{mmHg}$ dan diastolik di atas $90 \mathrm{mmHg}$. Pada populasi lansia, hipertensi didefinisikan sebagai tekanan sistolik $160 \mathrm{mmHg}$ dan tekanan diastolik $90 \mathrm{mmHg}$. Menurut WHO 1996, batasan tekanan darah normal orang dewasa adalah maksimum 140/90 mmHg. Apabila tekanan darah seseorang di atas angka tersebut pada beberapa kali pengukuran di waktu yang berbeda, orang tersebut bisa dikatakan menderita hipertensi. Hal yang menyebabkan klien mengalami peningkatan tekanan darah yaitu gaya hidup klien yang monoton, dikarenakan klien kalau dirumah jarang beraktifitas, hanya dirumah saja, kurang berolah raga, pola makan yang tidak baik dimana klien tidak suka 
mengkonsumsi sayur dan buah, klien lebih suka mengkonsumsi makanan yang berlemak dan kolesterol. Adapun keluhan yang menunjukkan tanda dan gejala penyakit hipertensi yaitu pusing, rasa berat di tengkuk, peningkatan tekanan darah dari batas normal, mual dan muntah.

\section{Daftar Pustaka}

Aprilawati Riza . (2012). Asuhan keperawatan pada Tn.H dengan hipertensi di bangsal Multazam rumah sakit pku Muhammadiyah Surakarta. Surakarta : Universitas Muhammadiyah Surakarta

Ibrahim.Asuhan Keperawatan Pada Lansia Dengan Hipertensi. Idea Nursing Journal. 2(1):60-70

Ni Ketut R.Ni ,Ketut G.Ngurah Gusti I.(2019). Gambaran Asuhan Keperawatan Keluarga Hipertensi Dengen Defisit Pengetahuan. Jurnal Gema Keperawatan 12 (2): $132-144$

Nurhidayat Saiful . (2015). Asuhan Keperawatan Pada Pasien Hipertensi . Ponorogo : :UNMUHPonorogo Press

Parwati,ni Nyoman. (2018). Asuhan keperawatan Keluarga dengan masalah utama hipertensi pada Tn.R Di wilayah kerja puskesmas mergangsan. Yogyakarta :politeknik kesehatan kementrian kesehatan

Rajab,Abdul Malik.(2018). Asuhan keperawatan gangguan pemenuhan kebutuhan dasar pada Tn.R dengan hipertensi di pavilliun Marwah atas Rs.islam Jakarta Cempaka putih. Jakarta : universitas Muhammadiyah Jakarta

Syamsinar Asmi Syamsinar A, Husaeni Hermin. (2019). Keperawatan Home Care Pada Keluarga dengan Masalah Kesehatan Hipertensi. Jurnal IImiah Kesehatan Sandi Husada.10(2):32-38

Simamora, R. H., Bukit, E., Purba, J. M., \& Siahaan, J. (2017). Penguatan kinerja perawat dalam pemberian asuhan keperawatan melalui pelatihan ronde keperawatan di rumah sakit royal prima medan. Jurnal pengabdian kepada masyarakat, 23(2), 300-304.

Simamora, R. H. (2019). Socialization of Information Technology Utilization and 
Knowledge of Information System Effectiveness at Hospital Nurses in Medan, North Sumatra. Editorial Preface From the Desk of Managing Editor..., 10(9).

Siregar, C. T. (2016). Pengalaman Pasien Hipertensi Primer Suku Minang Yang Menjalani Perawatan Di Rumah. NERS Jurnal Keperawatan, 12(1), 48-66.

Sumaryati, M. (2019). Studi Kasus Asuhan Keperawatan Gerontik Pada Keluarga Ny" M" Dengan Hipertensi Dikelurahan Barombong Kecamatan Tamalate Kota Makassar. Jurnal IImiah Kesehatan Sandi Husada, 6(2), 6-10.

Utami, P., Rahajeng, B., \& Soraya, C. (2019). Pengaruh Edukasi Home Pharmacy Care Terhadap Kualitas Hidup Pasien Hipertensi Di Puskesmas. Jurnal Farmasi Sains dan Praktis, 37-46. 